\title{
STEROLS HEATING: DEGRADATION AND FORMATION OF THEIR RING-STRUCTURE POLAR OXIDATION PRODUCTS
}

\author{
Author names and affiliations: Blanca Barriuso ${ }^{1}$, Ane Otaegui-Arrazola ${ }^{1}$, María \\ Menéndez-Carreño ${ }^{1,2}$, Iciar Astiasarán ${ }^{1}$, Diana Ansorena ${ }^{1}(*)$ \\ 1 Department of Nutrition, Food Science, Physiology and Toxicology. Faculty of \\ Pharmacy, University of Navarra, Irunlarrea s/n, 31008-Pamplona, Navarra, Spain. \\ bbarriuso@alumni.unav.es \\ aoarrazola@alumni.unav.es \\ iastiasa@unav.es \\ dansorena@unav.es
}

2 Department of Biochemistry and Cell Biology, Faculty of Veterinary Medicine, University of Utrecht, 3584 CM, The Netherlands.

M.MenendezCarreno@uu.nl

(*) Corresponding author

phone number: (0034) 948425600-6263;

fax number: 948425619;

e-mail: dansorena@,unav.es; 


\begin{abstract}
Cholesterol and phytosterols can suffer oxidation under heating conditions to give Sterol Oxidation Products (SOPs), known by their toxic effects. This paper studied the degradation of cholesterol and three plant sterols during a 360 min heating treatment $\left(180^{\circ} \mathrm{C}\right)$. The formation and further degradation of SOPs was also analyzed by GC-MS. Results revealed a sterol susceptibility to degradation according to the following decreasing order: campesterol $\approx \beta$-sitosterol $\geq$ stigmasterol $>$ cholesterol. Their degradation curve fit $\left(\mathrm{R}^{2}=0.907-0.979\right)$ a logarithmic model. Sterol Oxidation Products increased their concentration during the first 5-10 min and thereafter, their degradation rate was higher than their formation rate, resulting in a decrease over time. Irrespective of the sterol from which they had derived, 7-keto derivatives presented the highest levels throughout the entire process, and also SOPs with the same type of oxidation followed a similar degradation pattern $(\mathrm{R}=0.90-0.99)$.
\end{abstract}

\title{
KEYWORDS
}

Cholesterol; plant sterols; heating stability; degradation; kinetic models 


\section{INTRODUCTION}

Cholesterol and plant sterols can suffer autoxidation to give sterol oxidation products (SOPs), named COPs (cholesterol) and POPs (phytosterols), respectively. Some of these compounds have been demonstrated to exert harmful effects in the organism, including atherosclerosis, cytotoxicity and mutagenesis (Larsson, Baird, Nyhalah, Yuan, \& Li, 2006; Roussi, Gosse, Werner, Zhang, \& Marchioni, 2007; O'Callaghan, Foley, O'Connell, McCarthy, Maguire, \& O'Brien, 2010). The presence of polar SOPs has been widely reported in a great variety of foods, from vegetable oils to pork meat (OtaeguiArrazola, Menendez-Carreno, Ansorena, Astiasaran, 2010). Particular attention has been paid to the development of phytosterol-enriched functional foods due to their much higher sterol content compared to conventional foods. As a consequence, final oxysterol are also increased, reaching up to 3-5-fold compared to the non-enriched foods (Conchillo et al., 2005; Menéndez-Carreño, Ansorena, \& Astiasaran, 2008a). Assessing the perspectives of plant sterols-enriched food, particularly focusing on the occurrence of plant sterol oxidation products is of great interest (García-Llatas \& Rodríguez-Estrada, 2011). Not only their formation but also their degradation patterns should be studied in depth to predict their levels in foods. In order to avoid interferences of the food matrix and identify their net influence on the process, model systems are commonly used so that a better comprehension of the factors governing this issue can be obtained and a better control of certain food processing conditions might be consequently proposed.

Furthermore, there is also wide evidence of the capability of these compounds to be absorbed from the diet (Staprans, Pan, Rapp \& Feingold, 2005). Given the above- 
mentioned harmful effects in human cell lines, their formation should be minimized and the responsible factors should be studied in detail.

In this sense, factors such as high temperature and exposure to oxygen or light are responsible for oxysterols formation. Although 7-keto oxiderivatives are normally the

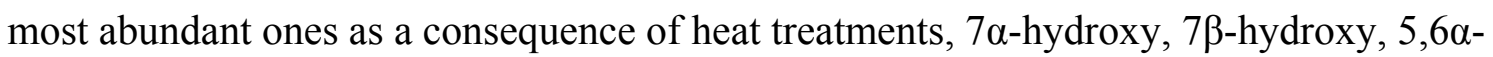
epoxy, 5,6ß-epoxy and 5,6,7-triol derivatives are usually analyzed, too (Lampi, Juntunen, Toivo, \& Piironen, 2002; Xu, Sun, Liang, Yang \& Chen, 2011). Degradation of both sterols and oxysterols occurs over $150^{\circ} \mathrm{C}$, giving rise to fragmented phytosterol molecules, volatile compounds and oligomers (Rudzinska, Przybylski \& Wasowicz, 2009; Struijs, Lampi, Ollilainen \& Piironen, 2010). $180^{\circ} \mathrm{C}$ is the temperature commonly chosen in most of the studies to evaluate sterol thermal susceptibility as it represents the more usual temperature applied in frying culinary processes. At this temperature, Menéndez-Carreño, Ansorena, Astiasaran, Piironen and Lampi. (2010) found a progressive decrease in stigmasterol content and formation and subsequent degradation of SOPs after one hour of heating. Nevertheless, this SOPs degradation has been reported to start at different moments of the heating process (Kemmo, Soupas, Lampi \& Piironen, 2005; Xu et al., 2011) depending on the experimental procedure, even when same temperature is applied.

Comparison between oxysterols derived from different initial sterols is a matter of great interest, which could contribute to complete a general overview. Some studies involving parallel monitoring of several sterols have been carried out (Grandgirard Martine, Joffre, Juaneda, \& Berdeaux, 2004; Menéndez-Carreño, Steenbergen, \& Janssen, 2011; González-Larena, Garcia-Llatas, Vidal, Sanchez-Siles, Barbera \& Lagarda 
2011). However, few of them assess a discussed comparison of relative degradation data (Cercaci et al., 2006; Menéndez-Carreño et al., 2008a) and the majority used a low number of sterols.

There are some studies concerning modelling with regression equations of cholesterol degradation as well as COPs formation(Chien, Wang \& Chen, 1998; Chien, Hsu \& Chen 2006; Yen, Inbaraj, Chien \& Chen 2010). However, to our knowledge, no study has dealt with plant sterols or SOPs degradation modelling and this would provide relevant information to estimate their actual levels.

Therefore, the aim of this work was to study the behaviour of three phytosterols ( $\beta$-sitosterol, stigmasterol and campesterol), as well as the formation and degradation pattern of six ring-structure polar oxidation products at $180^{\circ} \mathrm{C}$, comparing them to those of cholesterol. Non-linear regression models for the degradation curves of both sterols and oxysterols were designed.

\section{MATERIAL AND METHODS}

\subsection{Reagents}

Cholesterol, $5 \alpha$-cholestane and commercial mixtures of $\beta$-sitosterol, campesterol and stigmasterol were purchased from Sigma-Aldrich Chemical (Steinhei, Germany). 19hydroxycholesterol was purchased from Steraloids (Wilton, NH, USA). Tri-sil reagent was obtained from Pierce (Rockford, IL, USA). Acetone, chloroform, diethyl ether, methanol, hexane and 2-propanol were obtained from Panreac (Barcelona, Spain). Hexane for gas chromatography and dichloromethane for gas chromatography were from 
Merck (Whitehouse Station, NJ, USA). Sep-pack Vac 6cc silica 1g cartridges were obtained from Waters (Milford, USA).

\subsection{Heating of sterol samples}

Thermo-oxidation of sterol standards was done at $180{ }^{\circ} \mathrm{C}$ for various time durations: $0,5,10,20,30,60,90,120,180$ and $360 \mathrm{~min}$. For the thermo-oxidation, 0.5 $\mathrm{mL}$ of cholesterol standard solution $(5 \mathrm{mg} / \mathrm{mL})$ was added into 20 open glass vials $(15 \mathrm{x}$ $100 \mathrm{~mm}$ ). Half of the samples were used for the analysis of sterols and half of the samples for the determination of SOPs. The solvent was evaporated under gentle nitrogen stream. Subsequently, the vials were placed open (allowing enough oxygen disposal) in the Tembloc (P Selecta, Spain) previously stabilized at $180^{\circ} \mathrm{C}$. After the corresponding time, vials were taken out from heat. Same procedure was applied to the phytosterol standards solution $(5 \mathrm{mg} / \mathrm{mL} ; 3.29 \%$ campesterol, $0.40 \%$ campestanol, $53.81 \%$ stigmasterol, $37.33 \% \beta$-sitosterol and 5.18\% sitostanol). Then, the samples were maintained at room temperature for $20 \mathrm{~min}$, except for 5 and $10 \mathrm{~min}$ samples, which were cooled in ice for $5 \mathrm{~min}$ before acclimatization. After heating, samples presented an oily appearance. The experiment was performed in quadruplicate.

\subsection{Sterol analysis}

In order to get a similar concentration than that of phytosterols mixture samples, cholesterol heated samples were redissolved with $5 \mathrm{~mL}$ hexane/2-propanol $(3: 2, \mathrm{v} / \mathrm{v})$ and $1 \mathrm{~mL}$ was transferred into a new tube. Subsequently, $0.1 \mathrm{~mL}$ of $5 \alpha$-cholestane $(2 \mathrm{mg} / \mathrm{mL})$

was added to each cholesterol and phytosterol heated sample. The solvent was evaporated under gentle nitrogen stream. 
Both cholesterol and phytosterol heated samples were derivatized to trimethylsilyl (TMS) ethers according to a modified version of the method described by Dutta and Appelqvist (1997). $400 \mu \mathrm{L}$ of Tri-Sil reagent were added to each sample and they were kept at $60^{\circ} \mathrm{C}$ for $45 \mathrm{~min}$ in a water bath. The solvent was evaporated under a stream of nitrogen and the TMS-ether derivates were solved in $10 \mathrm{~mL}$ of hexane for gas chromatography. $400 \mu \mathrm{L}$ of this solution were filtrated with a syringe and a filter $(0.45 \mu \mathrm{m})$ and poured to a glass vial prior to GC-MS analysis.

Gas chromatography-Mass spectrometry (GC-MS) analysis was performed on a HP Hewlett Packard 6890 GC coupled to a HP 5973 Mass Selective Detector. The TMSether derivatives of cholesterol and phytosterol standards were separated on a capillary column Agilent 19091S-433 HP-5ms 5\% Phenyl Methyl Siloxane (30 m x $250 \mu \mathrm{m}$ x 0.25 $\mu \mathrm{m}$ film thickness) (Agilent, CA, USA). Oven temperature conditions had previously been optimized in order to achieve proper separation of the individual compounds. The program started at temperature of $85^{\circ} \mathrm{C}$, heated to $290^{\circ} \mathrm{C}$ at a rate of $50^{\circ} \mathrm{C} / \mathrm{min}$ and, finally, increased to $298^{\circ} \mathrm{C}$ at rate of $0.5^{\circ} \mathrm{C} / \mathrm{min}$. High purity helium was used as a carrier gas at a flow rate of $1 \mathrm{~mL} / \mathrm{min}$. The inlet pressure used was $9.64 \mathrm{psi}$. The injector temperature was $280^{\circ} \mathrm{C}$ and the samples were injected $(1 \mu \mathrm{L})$ in a splitless mode.

Peak identification was based on comparison of their mass spectra with the spectra of the Wiley library (HPCHEM, Wiley, 275, $6^{\text {th }}$ ed.) and also with those obtained from the literature. In some cases, a comparison of their retention time and MS fragments with those of standard pure compounds was also done. An internal standard method was used for quantification, with $5 \alpha$-cholestane as the internal standard. Cholesterol and $5 \alpha-$ cholestane quantification was made in SCAN, while plant sterols were quantified using 
selected ion monitoring (SIM) analysis on the basis of the amount of a specific ion for each peak (343, 484, 357, for campesterol, stigmasterol and $\beta$-sitosterol, respectively), and taking into account the relative abundance of each ion (Berasategi et al., 2012). Calibration curves were previously built. For the integration Agilent MSD Productivity ChemStation for GC and GC/MS Systems Data Analysis Application were used.

\subsection{Sterol Oxidation Products analysis}

The identification and quantification of sterol oxidation products was performed according to the validated method of Menéndez-Carreño et al. (2008b).

Firstly, $1 \mathrm{~mL}$ of internal standard (20 $\mu \mathrm{g} / \mathrm{mL}$ of 19 -hydroxycholesterol) was added to the heated samples. SPE was used to separate SOPs from non-polar and mid-polar products. The purification of oxysterols allows obtaining clear chromatograms. The SPE was made according to the procedures described in detail in Guardiola et al. (1995). The test tubes containing the samples diluted in $5 \mathrm{~mL}$ of hexane were applied to a SPE silica cartridge, previously equilibrated with $5 \mathrm{~mL}$ of hexane. The cartridge was subsequently treated with $10 \mathrm{~mL}$ of hexane:diethyl ether $(95: 5, \mathrm{v} / \mathrm{v}), 30 \mathrm{~mL}$ of hexane:diethyl ether (90:10, v/v), and with $10 \mathrm{~mL}$ of hexane:diethyl ether (80:20, v/v). Sterol oxidation products were finally eluted from the SPE cartridge with $10 \mathrm{~mL}$ of a mixture of acetone/methanol $(60: 20, \mathrm{v} / \mathrm{v})$. The solvent was evaporated in rotary evaporator under warm water bath $\left(35^{\circ} \mathrm{C}\right)$.

The sample solutions of sterol oxidation products were derivatized to trimethylsilyl (TMS) ethers as previously described for sterols.

GC-MS analysis was performed on a Hewlett Packard 6890N GC coupled to a 5975 Mass Selective Detector. The TMS-ether derivatives of sterol oxides were separated 
on a capillary column Agilent 19091S-433 HP-5ms 5\% Phenyl Methyl Siloxane (30 m x $250 \mu \mathrm{m} \times 0.25 \mu \mathrm{m}$ film thickness). Oven temperature conditions were as follows: initial temperature of $75^{\circ} \mathrm{C}$, heated to $250^{\circ} \mathrm{C}$ at a rate of $30^{\circ} \mathrm{C} / \mathrm{min}$, increased to $290^{\circ} \mathrm{C}$ at rate of $8^{\circ} \mathrm{C} / \mathrm{min}$, and finally, it was raised to $292^{\circ} \mathrm{C}$ at a rate of $0.5^{\circ} \mathrm{C} / \mathrm{min}$. High purity helium was used as a carrier gas at a flow rate of $1 \mathrm{~mL} / \mathrm{min}$. The inlet pressure used was 9.08 psi. The injector temperature was $250^{\circ} \mathrm{C}$ and the transfer line to detector $280^{\circ} \mathrm{C}$. The samples $(1 \mu \mathrm{L})$ were injected in splitless mode.

Peak identification was made following the same procedure as for sterols. SOPs quantification was also based on an internal standard method (19-hydroxycholesterol). It was performed using selected ion monitoring (SIM) analysis. For each stage of time, different ions (33) were selectively quantified and, consequently, extract ion chromatogram had to be used to integrate the corresponding peak areas. Given the lack of available POPs standards and their demonstrated similar to COPs response, COPs calibration curves assessed by Menendez-Carreño et al. (2008b) were also used to determine POPs content. For the integration Agilent MSD Productivity ChemStation for GC and GC/MS Systems Data Analysis Application (Agilent Technologies, Inc., CA, U.S.A.) were used.

\subsection{Statistical analysis}

For the statistical analysis of the data, SPSS 15.0 program (SPSS, Inc., Chicago, IL, U.S.A.) was used. Mean and standard deviation of data obtained from each replicate were calculated. For the mathematical modelling of the degradation of sterols and their oxides, the nonlinear regression analysis was used (from beginning in the case of sterols and from the moment of the maximum achieved in the case of SOPs). For the evaluation 
of the significant differences of the amounts of sterols and sterol oxides along time and among different sterols, one factor ANOVA with Tuckey post hoc multiple comparisons $(p<0.05)$ was applied. Finally, correlations between oxysterols of the same oxidation pattern (concerning functional group and position) but from different sterol origin were assessed by means of Pearson's correlation test.

\section{RESULTS}

\subsection{Sterol study}

Amounts of remaining cholesterol and phytosterols after the different heating times (0-360 min) are shown in Table 1. Significant differences were observed among every heating time during the first 20-30 min, when a drastic drop was detected.

Thereafter, small differences were found. Degradation reached around 55-60\% of the initial sterol content -except for cholesterol, $41.80 \%$ - during the first 5 min of treatment (Table 2). After 30 min heating, around $88 \%$ and $74.71 \%$ of the initial sterols had already been degraded, for phytosterols (mean value) and cholesterol, respectively. And around 90 and $79.64 \%$ respectively after $90 \mathrm{~min}$. At the end of the heat treatment all sterols were degraded up to around $95 \%$ of their initial level.

Different nonlinear regression models were assayed to predict the loss of sterols (logarithmic, inverse and exponential), with logarithmic model showing the highest $\mathrm{R}^{2}$ for all cases $(0.907,0.972,0.953$ and 0.979 for cholesterol, campesterol, stigmasterol and $\beta$-sitosterol, respectively). The plots and corresponding equations are shown in Figure 1. Cholesterol showed the highest first constant - named as $\alpha-(48.720)$ compared to the other equations (39.786 - 41.474). 


\subsection{Sterol Oxidation Products}

The evolution of 24 different SOPs was followed in this study. $7 \alpha$-hydroxy, $7 \beta$ -

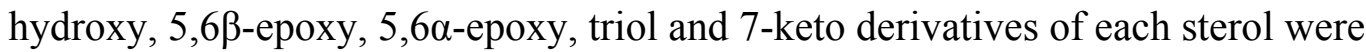
analyzed (Tables 3-6). The total amount of compounds derived from each sterol was also calculated (Figure 2). Maximum levels for each sterol total oxides were 73.79, 106.53, 49.75 and $98.38 \mu \mathrm{g} / \mathrm{mg}$, for cholesterol (10 $\mathrm{min})$, campesterol (10 $\mathrm{min})$, stigmasterol (5 $\min )$ and $\beta$-sitosterol (5 min), respectively. After this time, there was a significant and progressive decrease for total oxysterols, reaching minimal amounts, around $6 \%$ of the maximum concentration at the end of the process. Higher levels of total campesterol and $\beta$-sitosterol oxides were detected compared to those achieved by cholesterol and stigmasterol derivatives throughout the whole heating process.

The most abundant SOP formed was, by far, 7-ketosterol (irrespective of the type of sterol), reaching $64.28,65.93,53.85$ and $67.68 \%$ of the total amount of oxides derived from cholesterol, campesterol, stigmasterol and $\beta$-sitosterol, respectively, at the moment of the maximum total SOPs concentration, which was set at 5-10 min treatment. A trend to increase in all 7-keto plant sterol derivatives was observed at minute 60 , although not statistically significant. $7 \alpha$-hydroxy- and $7 \beta$-hydroxy- were the next derivatives formed from the quantitative point of view. While $7 \alpha$-hydroxy- derivatives were more abundant than $\beta$-hydroxy- ones at the initial points of analysis, as the treatment progressed, $\beta$ hydroxy- formation is favoured over alpha's. Sterol epoxides level is much smaller than 7-hydroxysterols' at the beginning (especially in the case of campesterol and stigmasterol), but higher at the end, ie, 8.09 and $21.11 \mu \mathrm{g} / \mathrm{mg}$ of $5,6 \alpha / \beta$-epoxycampesterol and $7 \alpha / \beta$-hydroxycampesterol respectively at $5 \mathrm{~min}$, compared to 5.89 and $0.52 \mu \mathrm{g} / \mathrm{mg}$ at 
90 min. Triol derivatives were the ones formed in a lower amount, even finding no campestanetriol.

As a similar behaviour could be observed among the same kind of oxysterols of different sterol origin (Table 1 and Figure 2), correlation was also studied among them, showing Pearson's Coefficients between 0.90 and 0.99 in most cases.

Among the different nonlinear regression models assayed (Table 7), and considering the $R^{2}$ values, the ones which best fit the degradation were for $7 \alpha$ and $7 \beta$ hydroxy, an inverse model; for 5,6 $\beta$-epoxy, a logarithmic model; and for the rest of compounds an exponential model -except for 5,6 $\alpha$-epoxycholesterol, which fit a logarithmic model-. In the overall view, total chol-ox, total cam-ox, total stigma-ox and total sito-ox followed an exponential-type degradation.

Concerning the degradation rate constants, $7 \alpha$-hydroxy compounds showed a degradation rate constant around twice that of 7 $\beta$-hydroxy, except for cholesterol samples. Among exponential regression adjustments, rate constants were in all cases ranging between -0.010 and -0.004 . Values were rather uniform within the same type of oxidation mechanism, regardless of the sterol origin -except for 5,6 $\alpha$-epoxycholesterol-, the constants of triol being the lowest (in absolute value) and that of 5,6 $\alpha$-epoxy the highest.

\section{DISCUSSION}

Compared to other studies performed both in model or real systems (Xu, Guan, Sun \& Chen, 2009; Yen et al., 2010; Menéndez-Carreño et al., 2010), the heat treatment conditions applied in our study seemed to be more destructive, since the degradation percentages of sterols were, in general, higher. Around 55\% degradation of cholesterol 
and $\beta$-sitosterol standards and 38\% stigmasterol standard have been previously reported after $1 \mathrm{~h}$ heating at $180^{\circ} \mathrm{C}$ (Xu et al., 2009; Menéndez-Carreño et al., 2010), compared to more than $70 \%$ noted for the present study. Different heating temperature/exposure time and other experimental conditions (such as initial sterol amount) could be behind this diversity of results. In their work, Menéndez-Carreño et al. (2010) heated the stigmasterol standard samples into glass vials placing them into an oven where the energy transfer takes place via convection heating. In contrast, sterol standards were heated in the present study by using an electronic heating device. Thus, the transfer of energy here occurs between two objects that are in physical contact (conduction heating). Then, as it has been suggested in several previous works, the sterol degradation pattern can differ significantly after the application of different heating technologies (Chien et al., 1998).

The comparison among the different degradation percentages of sterols showed a greater susceptibility to oxidation for phytosterols than for cholesterol, during first 120 min. Moreover, non-linear regression equation parameters for remaining sterol content also suggested a rather lower degradation intensity of cholesterol compared to plant sterols, attending to the value of the first constant, higher for cholesterol than for plant sterols As different initial amounts of sterols were used, interferences during oxidation could have occurred since thermo-oxidation is significantly dependent on the sample and to volume ratio (Lampi et al., 2002). In this sense, cholesterol particles would be less exposed to oxidation because of the highest initial amounts used $(2.5 \mathrm{mg})$. In this case, some controversial data can be observed in different works: Menéndez et al. (2008a) and Cercaci et al. (2006) found cholesterol to be more prone to oxidative degradation than $\beta$ sitosterol, whereas $\mathrm{Xu}$ et al. (2009) reported no differences in degradation rates among 
sterols. On basis on a kinetic study, Yen et al. (2010) and Chien et al. (1998) proposed first order equations for cholesterol degradation. Lower heating temperature $\left(150^{\circ} \mathrm{C}\right.$ instead of $180^{\circ} \mathrm{C}$ ) resulted in a slower degradation process, which could have lead to the adjustment of a first order equation with these parameters instead of a logarithmic one.

Regarding the accumulation of SOPs, maximum levels achieved were in accordance to the values found in the literature for cholesterol and $\beta$-sitosterol oxides, but slightly lower for campesterol and stigmasterol oxides (Xu et al., 2011; Yen et al, 2010; Kemmo, Ollilainen, Lampi, \& Piironen 2008; Lampi, Kemmo, Makela, Heikkinen \& Piironen, 2009). It is important to note that the maximum SOPs levels were reached at 5$10 \mathrm{~min}$, whereas other studies found maximum levels at 60 min or longer times at the same temperature $\left(180^{\circ} \mathrm{C}\right)(\mathrm{Xu}$ et al., 2011; Menéndez et al., 2010). These data pointed out that our degradation started earlier and higher concentrations could not have been achieved. The subsequent drastic drop was in accordance to what $\mathrm{Xu}$, Zhang, Prinyawiwatkul and Godber (2005) found, when heating cholesterol at $175^{\circ} \mathrm{C}$. Nevertheless, compared to other studies (Kemmo et al., 2005; Xu et al., 2011; Chien et al., 2006; Yen et al., 2010; Menéndez-Carreño et al., 2010), our degradation occurs much earlier, probably due to the different experimental conditions applied mentioned above. Changing processing temperatures have an important effect on the formation of oxysterols, but other experimental conditions are likely to contribute to differential results, ie different initial sample amounts, purification procedures or chromatographic techniques applied. Polymeric products, steradiens and both non-polar and mid-polar compounds have been reported as possible degradation products formed during extreme 
heating conditions (Menéndez-Carreño et al., 2010; Rudzinska et al., 2009; Lampi et al., 2009; Lercker and Estrada, 2002).

7-hydroxy and 7-keto oxides are usually expected to be the major SOPs (Grandgirard et al., 2004; González-Larena et al., 2011), at least during the first stages of oxidation. Dominancy of $\beta$-epimer among 7-hydroxy compounds is possibly due to stearic hindrance of the hydroxyl group at position 3 (Kemmo et al., 2005; Smith, 1987); other authors have also observed this trend (Lampi et al., 2002; Xu et al., 2005; Soupas Huikko, Lampi \& Piironen, 2007). The trend to increase in all 7-keto plant sterol oxides observed at minute 60 (Tables 3-6), might be attributed to the conversion from 7hydroxy derivatives (Rudzinska et al., 2009; Kemmo et al., 2008). Negligible levels of triol compounds have previously been reported (Conchillo et al., 2005; Lampi et al., 2002), only by heating treatments.

Regarding the higher levels of campesterol and $\beta$-sitosterol derivatives compared to that of cholesterol and stigmasterol ones, this behaviour could be attributed either to a faster oxidation of the campesterol and $\beta$-sitosterol to give rise to the corresponding oxides either to a slower degradation of these oxides. The lower initial amounts of campesterol (0.081 mg) and $\beta$-sitosterol $(0.916 \mathrm{mg})$ could be behind this behaviour (Lampi et al., 2002), since it would have been overexposed to oxygen. In addition, the presence of an extra double bound in the side chain of stigmasterol at position 22 may possibly have affected to the rate of oxidation of this compound. Thus, stigmasterol presented the lowest total maximum amount of oxidation products especially affecting 7ketostigmasterol formation in comparison to the other sterols. Nevertheless, further research would be necessary to confirm this hypothesis. 
Considering comparative graphs and kinetic curves, it can be stated that oxysterols followed a tendency according to the type of oxidation, and regardless of the sterol origin. However, a particular case can be highlighted: 5,6 $\alpha$-epoxycholesterol presented its best adjustment for a logarithmic model, whereas plant sterols analogous oxides were adjusted to an exponential one. Different side chain could be behind this behaviour, although further studies would be required to make more accurate conclusions. Drastic drop of 7-hydroxy derivatives levels (Tables 3-6) could be related to their adjustment to an inverse model, instead of an exponential one, as in the other cases.

In conclusion, our results revealed a sterol susceptibility to degradation following this decreasing order: campesterol $\approx \beta$-sitosterol $\geq$ stigmasterol $>$ cholesterol. Regarding Sterol Oxidation Products, the levels increased during the first 5-10 min and thereafter, their degradation rate was higher than their formation rate. SOPs degradation seemed to depend on the molecular structure of the oxidized compound, irrespective of the sterol from which they were derived.

\section{Acknowledgements}

We thank the "Programa Consolider-Ingenio 2010 CARNISENUSA CSD 2007-00016", the "Proyecto AGL2008-01099/ALI" (Ministerio de Ciencia e Innovación), and "Plan Investigador de la Universidad de Navarra" (PIUNA) for their contribution to the financial support of this work. B. Barriuso is grateful to "Cátedra Tomás Pascual SanzUniversidad de Navarra" and to "Asociación de Amigos de la Universidad de Navarra" for the Grants received.

\section{References}


Berasategi, I., Barriuso, B., Ansorena, D., \& Astiasarán, I. (2012). Stability of avocado oil during heating: Comparative study to olive oil. Food Chemistry, 132, 439-446

Cercaci, L., Conchillo, A., Rodriguez-Estrada, M., Ansorena, D., Astiasaran, I., Conchillo, A., \& Lercker, G. (2006). Preliminary study on health-related lipid components of bakery products. Journal of Food Protection, 69(6), 1393-1401.

Chien, J., Wang, H., \& Chen, B. (1998). Kinetic model of the cholesterol oxidation during heating. Journal of Agricultural and Food Chemistry, 46(7), 2572-2577.

Chien, J. T., Hsu, D. J., \& Chen, B. H. (2006). Kinetic model for studying the effect of quercetin on cholesterol oxidation during heating. Journal of Agricultural and Food Chemistry, 54(4), 1486-1492.

Conchillo, A., Cercaci, L., Ansorena, D., Rodriguez Estrada, M., Lercker, G., Cercaci, L., \& Astiasaran, I. (2005). Levels of phytosterol oxides in enriched and nonenriched spreads: Application of a thin-layer chromatography-gas chromatography methodology. Journal of Agricultural and Food Chemistry, 53(20), 7844-7850.

Dutta, P., \& Appelqvist, L. (1997). Studies on phytosterol oxides .1. effect of storage on the content in potato chips prepared in different vegetable oils. Journal of the American Oil Chemists' Society, 74(6), 647-657.

Garcia-Llatas, G., \& Rodriguez-Estrada, M. (2011). Current and new insights on phytosterol oxides in plant sterol-enriched food. Chemistry and Physics of Lipids, 164(6), 607-624. 
Gonzalez-Larena, M., Garcia-Llatas, G., Vidal, M., Sanchez-Siles, L., Barbera, R., \& Lagarda, M. (2011). Stability of plant sterols in ingredients used in functional foods. Journal of Agricultural and Food Chemistry, 59(8), 3624-3631.

Grandgirard, A., Martine, L., Joffre, C., Juaneda, P., \& Berdeaux, O. (2004). Gas chromatographic separation and mass spectrometric identification of mixtures of oxyphytosterol and oxycholesterol derivatives - application to a phytosterol-enriched food. Journal of Chromatography a, 1040(2), 239-250.

Guardiola, F., Codony, R., Rafecas, M., \& Boatella, J. (1995). Comparison of 3 methods for determination of oxysterols in spray-dried egg. Journal of Chromatography, 705(2), 289-304.

Kemmo, S., Soupas, L., Lampi, A. M., \& Piironen, V. (2005). Formation and decomposition of stigmasterol hydroperoxides and secondary oxidation products during thermo-oxidation. European Journal of Lipid Science and Technology, 107(11), 805-814.

Kemmo, S., Ollilainen, V., Lampi, A. M., \& Piironen, V. (2008). Liquid chromatography mass spectrometry for plant sterol oxide determination in complex mixtures. European Food Research and Technology, 226(6), 1325-1334.

Lampi, A., Juntunen, L., Toivo, J., \& Piironen, V. (2002). Determination of thermooxidation products of plant sterols. Journal of Chromatography.B, 777(1-2), 83-92. 
Lampi, A., Kemmo, S., Makela, A., Heikkinen, S., \& Piironen, V. (2009). Distribution of monomeric, dimeric and polymeric products of stigmasterol during thermooxidation. European Journal of Lipid Science and Technology, 111(10), 1027-1034.

Larsson, D., Baird, S., Nyhalah, J., Yuan, X., \& Li, W. (2006). Oxysterol mixtures, in atheroma-relevant proportions, display synergistic and proapoptotic effects. Free Radical Biology Medicine, 41(6), 902-910.

Lercker, G., \& Rodríguez-Estrada, M.T. (2002) Cholesterol oxidation mechanisms. In. Guardiola, F., Dutta, P.C., Codony, R. Savage, G.P. (Eds.), Cholesterol and phytosterol oxidation products: Analysis, Occurrence, and Biological Effects (1, 125). AOCS Publishing, Champaign.

Menéndez-Carreno, M., Ansorena, D., \& Astiasaran, I. (2008a). Stability of sterols in phytosterol-enriched milk under different heating conditions. Journal of Agricultural and Food Chemistry, 56(21), 9997-10002.

Menendez-Carreno, M., Garcia Herreros, C., Astiasaran, I., \& Ansorena, D. (2008b). Validation of a gas chromatography-mass spectrometry method for the analysis of sterol oxidation products in serum. Journal of Chromatography.B, 864(1-2), 61-68.

Menendez-Carreno, M., Ansorena, D., Astiasaran, I., Piironen, V., \& Lampi, A. (2010). Determination of non-polar and mid-polar monomeric oxidation products of stigmasterol during thermo-oxidation. Food Chemistry, 122(1), 277-284. 
Menéndez-Carreño, M., Steenbergen, H., \& Janssen, H.G. Development and validation of a comprehensive two-dimensional gas chromatography-mass spectrometry method for the analysis of phytosterol oxidation products in human plasma. Analytical and Bioanalytical Chemistr. In press.

O'Callaghan, Y., Foley, D., O'Connell, N., McCarthy, F., Maguire, A., \& O'Brien, N. (2010). Cytotoxic and apoptotic effects of the oxidized derivatives of stigmasterol in the U937 human monocytic cell line. Journal of Agricultural and Food Chemistry, 58(19), 10793-10798.

Otaegui-Arrazola, A., Menendez-Carreno, M., Ansorena, D., Astiasaran, I., MenndezCarreo, M., \& Astiasarn, I. (2010). Oxysterols: A world to explore. Food and Chemical Toxicology, 48(12), 3289-3303.

Roussi, S., Gosse, F., Aoude Werner, D., Zhang, X., \& Marchioni, E. (2007). Mitochondrial perturbation, oxidative stress and lysosomal destabilization are involved in 7 beta-hydroxysitosterol and 7 beta-hydroxycholesterol triggered apoptosis in human colon cancer cells. Apoptosis, 12(1), 87-96.

Rudzinska, M., Przybylski, R., \& Wasowicz, E. (2009). Products formed during thermooxidative degradation of phytosterols. Journal of the American Oil Chemists' Society, 86(7), 651-662.

Smith, L. L. (1987). Cholesterol autoxidation 1981-1986. Chemistry and Physics of Lipids, 44(2-4), 87-125. 
Soupas, L., Huikko, L., Lampi, A., \& Piironen, V. (2007). Pan-frying may induce phytosterol oxidation. Food Chemistry, 101(1), 286-297.

Staprans, I., Pan, X. M., Rapp, J. H., \& Feingold, K. R. (2005). The role of dietary oxidized cholesterol and oxidized fatty acids in the development of atherosclerosis. Molecular Nutrition \& Food Research, 49(11), 1075-1082.

Struijs, K., Lampi, A., Ollilainen, V., \& Piironen, V. (2010). Dimer formation during the thermo-oxidation of stigmasterol. European Food Research and Technology, 231(6), 853-863.

Xu, Z. M., Zhang, T., Prinyawiwatkul, W., \& Godber, J. S. (2005). Capabilities of different cooking oils in prevention of cholesterol oxidation during heating. Journal of the American Oil Chemists Society, 82(4), 243-248.

Xu, G., Guan, L., Sun, J., \& Chen, Z. (2009). Oxidation of cholesterol and beta-sitosterol and prevention by natural antioxidants. Journal of Agricultural and Food Chemistry, 57(19), 9284-9292.

Xu, G. H., Sun, J. L., Liang, Y. T., Yang, C., \& Chen, Z. Y. (2011). Interaction of fatty acids with oxidation of cholesterol and beta-sitosterol. Food Chemistry, 124(1), 162170.

Yen, T., Inbaraj, B., Chien, J., \& Chen, B. (2010). Gas chromatography-mass spectrometry determination of conjugated linoleic acids and cholesterol oxides and their stability in a model system. Analytical Biochemistry, 400(1), 130-138. 


\section{FIGURE CAPTIONS:}

Figure 1. Mathematical modeling of the degradation of sterol standards during 360-minute thermooxidation at $180^{\circ} \mathrm{C}$. Remaining percentages of a) Cholesterol b) Campesterol c) Stigmasterol d) $\beta$-sitosterol

Figure 2. Graphic representations of total SOPs during thermo-oxidation $\left(180^{\circ} \mathrm{C}\right)$ up to $360 \mathrm{~min}$ for different sterol origins - - - cholesterol —- campesterol —- stigmasterol $\longrightarrow$ - sitosterol 
Table 1. Degradation of sterol standards during 360-minute thermo oxidation at $180^{\circ} \mathrm{C}$. Mean and standard deviation $(n=4)$ are represented with the statistical analysis. Different letters within each column denote significant differences among heating times $(\mathrm{p}<0.05)$.

\begin{tabular}{|c|c|c|c|c|c|c|c|c|}
\hline \multirow{3}{*}{$\begin{array}{c}\begin{array}{c}\text { Time } \\
\text { (min) }\end{array} \\
0\end{array}$} & \multicolumn{8}{|c|}{ Remaining sterols (mg) } \\
\hline & \multicolumn{2}{|c|}{ cholesterol } & \multicolumn{2}{|c|}{ campesterol } & \multicolumn{2}{|c|}{ stigmasterol } & \multicolumn{2}{|c|}{ sitosterol } \\
\hline & 2.41 & $\pm 0.05^{g}$ & 0.08 & $\pm 0.01^{\mathrm{e}}$ & 1.32 & $\pm 0.10^{d}$ & 0.92 & $\pm 0.07^{f}$ \\
\hline 5 & 1.40 & $\pm 0.16^{\dagger}$ & 0.03 & $\pm 0.01^{d}$ & 0.58 & $\pm 0.07^{c}$ & 0.35 & $\pm 0.03^{\mathrm{e}}$ \\
\hline 10 & 1.07 & $\pm 0.21^{\mathrm{e}}$ & 0.02 & $\pm 0.003^{c}$ & 0.48 & $\pm 0.06^{c}$ & 0.23 & $\pm 0.03^{d}$ \\
\hline 20 & 0.88 & $\pm 0.02^{d}$ & 0.01 & $\pm 0.001^{b}$ & 0.25 & $\pm 0.02^{b}$ & 0.15 & $\pm 0.02^{c}$ \\
\hline 30 & 0.61 & $\pm 0.01^{c}$ & 0.01 & $\pm 0.001^{a b}$ & 0.16 & $\pm 0.02^{\mathrm{ab}}$ & 0.10 & $\pm 0.01^{\mathrm{bc}}$ \\
\hline 60 & 0.55 & $\pm 0.02^{b c}$ & 0.01 & $\pm 0.001^{a b}$ & 0.13 & $\pm 0.003^{a}$ & 0.10 & $\pm 0.01 \mathrm{bc}$ \\
\hline 90 & 0.49 & $\pm 0.02 \mathrm{bc}$ & 0.01 & $\pm 0.001^{a b}$ & 0.12 & $\pm 0.003^{a}$ & 0.09 & $\pm 0.01 \mathrm{bc}$ \\
\hline 120 & 0.38 & $\pm 0.01^{b}$ & 0.01 & $\pm 0.001^{a b}$ & 0.10 & $\pm 0.004^{a}$ & 0.08 & $\pm 0.00^{\mathrm{ab}}$ \\
\hline 180 & 0.16 & $\pm 0.01^{a}$ & 0.01 & $\pm 0.001^{a}$ & 0.09 & $\pm 0.002^{a}$ & 0.07 & $\pm 0.001^{a b}$ \\
\hline 360 & 0.13 & $\pm 0.01^{\mathrm{a}}$ & 0.01 & $\pm 0.001^{a}$ & 0.05 & $\pm 0.002^{a}$ & 0.04 & $\pm 0.001^{a}$ \\
\hline
\end{tabular}


Table 2. Degradation percentages of cholesterol, campesterol, stigmasterol and sitosterol during 360-minute thermo oxidation at $180^{\circ} \mathrm{C}$. Within each row, different letters denote significant differences $(\mathrm{p}<0.05)$ among sterols.

\begin{tabular}{|c|c|c|c|c|c|c|c|c|}
\hline \multirow{3}{*}{$\begin{array}{c}\begin{array}{c}\text { Time } \\
\text { (min) }\end{array} \\
5\end{array}$} & \multicolumn{8}{|c|}{ Degradation percentages (\%) } \\
\hline & \multicolumn{2}{|c|}{ cholesterol } & \multicolumn{2}{|c|}{ campesterol } & \multicolumn{2}{|c|}{ stigmasterol } & \multicolumn{2}{|c|}{ sitosterol } \\
\hline & 41.80 & $\pm 7.23^{\mathrm{a}}$ & 58.06 & $\pm 5.83^{b}$ & 56.12 & $\pm 5.84^{\mathrm{ab}}$ & 61.45 & $\pm 3.41^{b}$ \\
\hline 10 & 55.74 & $\pm 9.75^{a}$ & 71.56 & $\pm 389^{b}$ & 63.47 & $\pm 4.71^{\mathrm{ab}}$ & 74.68 & $\pm 3.65^{b}$ \\
\hline 20 & 63.58 & $\pm 0.75^{a}$ & 82.68 & $\pm 1.83^{b}$ & 80.87 & $\pm 1.78^{b}$ & 83.89 & $\pm 1.73^{b}$ \\
\hline 30 & 74.71 & $\pm 0.66^{a}$ & 87.06 & $\pm 1.31^{b}$ & 88.30 & $\pm 1.38^{b}$ & 88.72 & $\pm 1.14^{b}$ \\
\hline 60 & 76.99 & $\pm 0.75^{a}$ & 87.16 & $\pm 1.22^{b}$ & 90.40 & $\pm 0.26^{c}$ & 89.31 & $\pm 0.79^{c}$ \\
\hline 90 & 79.64 & $\pm 0.76^{a}$ & 88.14 & $\pm 0.40^{b}$ & 90.87 & $\pm 0.26^{d}$ & 89.73 & $\pm 0.53^{c}$ \\
\hline 120 & 84.37 & $\pm 0.35^{a}$ & 89.60 & $\pm 0.27^{b}$ & 92.20 & $\pm 0.27^{d}$ & 91.42 & $\pm 0.28^{c}$ \\
\hline 180 & 93.25 & $\pm 0.53^{c}$ & 90.89 & $\pm 0.35^{\mathrm{a}}$ & 93.22 & $\pm 0.17^{c}$ & 92.40 & $\pm 0.15^{b}$ \\
\hline 360 & 94.51 & $\pm 0.54^{a}$ & 94.34 & $\pm 0.20^{\mathrm{a}}$ & 96.39 & $\pm 0.14^{b}$ & 95.79 & $\pm 0.14^{b}$ \\
\hline
\end{tabular}


1 Table 3. Concentration of cholesterol oxidation products ( $\mu \mathrm{g} / \mathrm{mg})$. Mean and standard deviation (SD) during thermo oxidation at $180{ }^{\circ} \mathrm{C}$ analysed by GC-MSD. Within each 2 column, different letters denote significant differences among heating times $(\mathrm{p}<0.05)$.

\begin{tabular}{|c|c|c|c|c|c|c|c|c|c|c|c|c|}
\hline \multirow{3}{*}{$\begin{array}{c}\begin{array}{c}\text { Time } \\
(\mathrm{min})\end{array} \\
0\end{array}$} & \multicolumn{12}{|c|}{ cholesterol oxides ( $\mu \mathrm{g} / \mathrm{mg}$ cholesterol) } \\
\hline & \multirow{2}{*}{\multicolumn{2}{|c|}{$\frac{\text { 7a-hydroxy }}{\text { nd (not detected) }}$}} & \multicolumn{2}{|c|}{ 7ß-hydroxy } & \multicolumn{2}{|c|}{ 5,6ß-ероху } & \multicolumn{2}{|c|}{ 5,6-a-epoxy } & \multicolumn{2}{|r|}{ triol } & \multicolumn{2}{|c|}{ 7-keto } \\
\hline & & & nd & - & 0.08 & $\pm 0.01^{a}$ & 0.25 & $\pm 0.01^{\mathrm{a}}$ & nd & - & nd & - \\
\hline 5 & 5.26 & $\pm 0.35^{c}$ & 3.60 & $\pm 0.36^{c}$ & 3.85 & $\pm 0.30^{c}$ & 3.62 & $\pm 0.36^{c}$ & 0.26 & $\pm 0.05^{\mathrm{de}}$ & 35.83 & $\pm 5.57^{\text {ef }}$ \\
\hline 10 & 7.05 & $\pm 0.83^{d}$ & 6.83 & $\pm 0.74^{d}$ & 5.42 & $\pm 0.77^{d}$ & 6.79 & $\pm 1.12^{\mathrm{e}}$ & 0.26 & $\pm 0.05^{\mathrm{de}}$ & 47.43 & $\pm 6.80^{g}$ \\
\hline 20 & 2.76 & $\pm 0,39^{b}$ & 5.64 & $\pm 1.01^{\mathrm{e}}$ & 3.21 & $\pm 0.37^{c}$ & 5.14 & $\pm 0.20^{d}$ & 0.28 & $\pm 0.04^{\mathrm{de}}$ & 41.86 & $\pm 1.77^{\mathrm{fg}}$ \\
\hline 30 & 0.78 & $\pm 0.15^{\mathrm{a}}$ & 1.49 & $\pm 0.11^{b}$ & 1.46 & $\pm 0.25^{b}$ & 3.88 & $\pm 0.45^{c}$ & 0.25 & $\pm 0.02^{\mathrm{de}}$ & 34.40 & $\pm 2.65^{\text {ef }}$ \\
\hline 60 & 0.55 & $\pm 0.02^{a}$ & 0.93 & $\pm 0.01^{a b}$ & 0.72 & $\pm 0.08^{a b}$ & 3.03 & $\pm 0.23^{b}$ & 0.31 & $\pm 0.04^{\mathrm{e}}$ & 31.18 & $\pm 4.63^{\mathrm{e}}$ \\
\hline 90 & nd & - & nd & - & 0.09 & $\pm 0.02^{a}$ & 0.68 & $\pm 0.13^{a}$ & 0.24 & \pm 0.01 de & 21.22 & $\pm 2.80^{d}$ \\
\hline 120 & nd & - & nd & - & 0.04 & $\pm 0.01^{a}$ & 0.40 & $\pm 0.08^{a}$ & 0.20 & $\pm 0.03^{c d}$ & 17.07 & $\pm 2.55^{\mathrm{cd}}$ \\
\hline 180 & nd & - & nd & - & 0.02 & $\pm 0.001^{a}$ & 0.23 & $\pm 0.02^{a}$ & 0.12 & $\pm 0.004^{b c}$ & 10.76 & $\pm 0.64^{b c}$ \\
\hline 360 & nd & - & nd & - & 0.01 & $\pm 0.001^{a}$ & 0.12 & $\pm 0.01^{a}$ & 0.05 & $\pm 0.01^{\mathrm{ab}}$ & 3.32 & $\pm 0.41^{a b}$ \\
\hline
\end{tabular}


4 Table 4. Concentration of campesterol oxidation products ( $\mu \mathrm{g} / \mathrm{mg}$ ). Mean and standard deviation (SD) during thermo oxidation at $180^{\circ} \mathrm{C}$ analysed by GC-MSD. Within each 5 column, different letters denote significant differences among heating times $(\mathrm{p}<0.05)$.

\begin{tabular}{|c|c|c|c|c|c|c|c|c|c|c|c|c|}
\hline \multirow{3}{*}{$\begin{array}{c}\begin{array}{c}\text { Time } \\
(\mathrm{min})\end{array} \\
0\end{array}$} & \multicolumn{12}{|c|}{ campesterol oxides ( $\mu \mathrm{g} / \mathrm{mg}$ campesterol) } \\
\hline & \multirow{2}{*}{\multicolumn{2}{|c|}{$\frac{\text { 7a-hydroxy }}{\text { nd (not detected) }}$}} & \multicolumn{2}{|c|}{ 7ß-hydroxy } & \multicolumn{2}{|c|}{$5,6 \beta$-epoxy } & \multicolumn{2}{|c|}{ 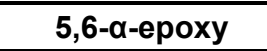 } & \multicolumn{2}{|c|}{ triol } & \multicolumn{2}{|c|}{ 7-keto } \\
\hline & & & nd & - & 0.38 & $\pm 003^{a}$ & 0.001 & $\pm 0.000^{a}$ & nd & - & 0.09 & $\pm 0.03^{\mathrm{a}}$ \\
\hline 5 & 14.06 & $\pm 2.32^{c}$ & 7.05 & $\pm 0.25^{d}$ & 0.79 & $\pm 0.11^{a b}$ & 7.30 & $\pm 0.28^{\text {ef }}$ & nd & - & 70.23 & $\pm 7.12^{\mathrm{e}}$ \\
\hline 10 & 16.85 & $\pm 1.59^{c}$ & 7.19 & $\pm 1.24^{d}$ & 1.49 & $\pm 0.20^{c}$ & 10.13 & $\pm 0.94^{g}$ & nd & - & 70.87 & $\pm 8.74^{\mathrm{e}}$ \\
\hline 20 & 8.30 & $\pm 0.71^{b}$ & 4.66 & $\pm 0.95^{c}$ & 1.47 & $\pm 0.03^{b c}$ & 7.61 & $\pm 0.80^{f}$ & nd & - & 52.01 & $\pm 6.41^{d}$ \\
\hline 30 & 1.89 & $\pm 0.31^{a}$ & 2.52 & $\pm 0.27^{b}$ & 124 & $\pm 0.17^{b c}$ & 6.23 & $\pm 0.66^{\mathrm{de}}$ & nd & - & 43.25 & $\pm 0.27^{\mathrm{cd}}$ \\
\hline 60 & 0.89 & $\pm 0.14^{a}$ & 1.11 & $\pm 0.03^{a b}$ & 1.54 & $\pm 0.26^{c}$ & 4.91 & $\pm 0.57^{\mathrm{cd}}$ & nd & - & 52.96 & $\pm 2.60^{d}$ \\
\hline 90 & 0.20 & $\pm 0.01^{a}$ & 0.33 & $\pm 0.06^{a}$ & 1.62 & $\pm 0.30^{c}$ & 4.27 & $\pm 0.61^{c}$ & nd & - & 38.71 & $\pm 2.32^{c}$ \\
\hline 120 & nd & - & 0.12 & $\pm 0.02^{a}$ & 1.47 & $\pm 0.30^{b c}$ & 2.65 & $\pm 0.37^{b}$ & nd & - & 33.19 & $\pm 4.17^{b c}$ \\
\hline 180 & nd & - & 0.11 & $\pm 0.02^{a}$ & 1.33 & $\pm 0.17^{b c}$ & 2.09 & $\pm 0.26^{b}$ & nd & - & 24.18 & $\pm 4.00^{b}$ \\
\hline 360 & nd & - & 0.06 & $\pm 0.005^{a}$ & 0.44 & $\pm 0.05^{\mathrm{a}}$ & 0.59 & $\pm 0.10^{a}$ & nd & - & 7.90 & $\pm 0.50^{a}$ \\
\hline
\end{tabular}


9 Table 5. Concentration of stigmasterol oxidation products $\left(\mu \mathrm{g} / \mathrm{mg}\right.$ ). Mean and standard deviation (SD) during thermo oxidation at $180^{\circ} \mathrm{C}$ analysed by GC-MSD. Within each 10 column, different letters denote significant differences among heating times $(\mathrm{p}<0.05)$.

\begin{tabular}{|c|c|c|c|c|c|c|c|c|c|c|c|c|}
\hline \multirow{3}{*}{$\begin{array}{c}\begin{array}{c}\text { Time } \\
\text { (min) }\end{array} \\
0\end{array}$} & \multicolumn{12}{|c|}{ stigmasterol oxides ( $\mu \mathrm{g} / \mathrm{mg}$ stigmasterol) } \\
\hline & \multicolumn{2}{|c|}{ 7a-hydroxy } & \multicolumn{2}{|c|}{ 7ß-hydroxy } & \multicolumn{2}{|c|}{ 5,6ß-ероху } & \multicolumn{2}{|c|}{ 5,6-a-epoxy } & \multicolumn{2}{|r|}{ triol } & \multicolumn{2}{|c|}{ 7-keto } \\
\hline & 0.08 & $\pm 0.01^{\mathrm{a}}$ & 0.03 & $\pm 0.004^{\mathrm{a}}$ & 0.01 & $\pm 0.001^{\mathrm{a}}$ & nd ( & t detected) & nd & - & 0.03 & $\pm 0.01^{\mathrm{a}}$ \\
\hline 5 & 9.96 & $\pm 1.46^{c}$ & 5.01 & $\pm 0.25^{d}$ & 4.77 & $\pm 0.08^{d}$ & 2.79 & $\pm 0.55^{\mathrm{de}}$ & 0.44 & $\pm 0.08^{b c}$ & 26.79 & $\pm 4.33^{f}$ \\
\hline 10 & 11.15 & $\pm 1.92^{c}$ & 5.02 & $\pm 0.76^{d}$ & 4.69 & $\pm 0.85^{d}$ & 3.44 & $\pm 0.40^{\mathrm{e}}$ & 0.87 & $\pm 0.13^{f}$ & 23.61 & $\pm 2.74^{f}$ \\
\hline 20 & 6.20 & $\pm 0.75^{b}$ & 3.37 & $\pm 0.63^{c}$ & 3.94 & $\pm 0.67^{d}$ & 2.44 & $\pm 0.29^{c d}$ & 0.81 & $\pm 0.07^{\text {ef }}$ & 17.09 & $\pm 2.59^{\mathrm{e}}$ \\
\hline 30 & 1.33 & $\pm 0.23^{a}$ & 1.74 & $\pm 0.11^{b}$ & 2.13 & $\pm 0.36^{c}$ & 1.88 & $\pm 0.19^{b c}$ & 0.70 & $\pm 0.03^{\text {def }}$ & 13.83 & $\pm 0.59^{\mathrm{de}}$ \\
\hline 60 & 0.51 & $\pm 0.06^{a}$ & 0.68 & $\pm 0.03^{a b}$ & 1.44 & $\pm 0.11^{b c}$ & 1.53 & $\pm 0.14^{b}$ & 0.65 & $\pm 0.11^{\mathrm{de}}$ & 16.16 & $\pm 2.42^{\mathrm{e}}$ \\
\hline 90 & 0.15 & $\pm 0.02^{a}$ & 0.25 & $\pm 0.05^{\mathrm{a}}$ & 1.05 & $\pm 0.10^{\mathrm{abc}}$ & 1.38 & $\pm 0.26^{b}$ & 0.61 & $\pm 0.11^{\mathrm{cd}}$ & 13.04 & $\pm 1.22^{\mathrm{de}}$ \\
\hline 120 & 0.06 & $\pm 0.01^{a}$ & 0.09 & $\pm 0.02^{a}$ & 0.59 & $\pm 0.07^{\mathrm{ab}}$ & 0.57 & $\pm 0.07^{a}$ & 0.46 & $\pm 0.02^{b c}$ & 8.85 & $\pm 0.15^{c d}$ \\
\hline 180 & 0.06 & $\pm 0.01^{a}$ & 0.07 & $\pm 0.008^{a}$ & 0.45 & $\pm 0.09^{a b}$ & 0.45 & $\pm 0.09^{a}$ & 0.31 & $\pm 0.05^{b}$ & 6.86 & $\pm 0.75^{b c}$ \\
\hline 360 & 0.01 & $\pm 0.00^{a}$ & 0.02 & $\pm 0.002^{a}$ & 0.07 & $\pm 0.01^{a}$ & 0.10 & $\pm 0.02^{a}$ & 0.05 & $\pm 0.01^{a}$ & 2.51 & $\pm 0.11^{\mathrm{ab}}$ \\
\hline
\end{tabular}

12 
13 Table 6. Concentration of $\beta$-sitosterol oxidation products $(\mu \mathrm{g} / \mathrm{mg})$. Mean and standard deviation (SD) during thermo oxidation at $180^{\circ} \mathrm{C}$ analysed by GC-MSD. Within each 14 column, different letters denote significant differences among heating times $(\mathrm{p}<0.05)$.

\begin{tabular}{|c|c|c|c|c|c|c|c|c|c|c|c|c|}
\hline \multirow{3}{*}{$\begin{array}{c}\begin{array}{c}\text { Time } \\
\text { (min) }\end{array} \\
0\end{array}$} & \multicolumn{12}{|c|}{ sitosterol oxides ( $\mu \mathrm{g} / \mathrm{mg} \beta$-sitosterol) } \\
\hline & \multicolumn{2}{|c|}{ 7a-hydroxy } & \multicolumn{2}{|c|}{ 7ß-hydroxy } & \multirow{2}{*}{\multicolumn{2}{|c|}{$\begin{array}{c}\text { 5,6 } \beta \text {-epoxy } \\
\text { nd (not detected) }\end{array}$}} & \multicolumn{2}{|c|}{ 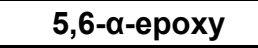 } & \multicolumn{2}{|r|}{ triol } & \multicolumn{2}{|c|}{ 7-keto } \\
\hline & 0.06 & $\pm 0.01^{\mathrm{a}}$ & 0.02 & $\pm 0.00^{\mathrm{a}}$ & & & 0.001 & $\pm 0.003^{a}$ & nd & - & 0.04 & $\pm 0.01^{\mathrm{a}}$ \\
\hline 5 & 12.27 & $\pm 1.69^{c}$ & 6.86 & $\pm 0.25^{d}$ & 5.80 & $\pm 0.56^{d}$ & 6.05 & $\pm 0.58^{\mathrm{e}}$ & 0.82 & $\pm 0.13^{\mathrm{e}}$ & 66.58 & $\pm 12.73^{f}$ \\
\hline 10 & 13.94 & $\pm 2.44^{c}$ & 7.04 & $\pm 1.10^{d}$ & 5.58 & $\pm 0.67^{d}$ & 8.36 & $\pm 0.64^{d}$ & 0.56 & $\pm 0.06^{d}$ & 59.17 & $\pm 11.12^{\text {ef }}$ \\
\hline 20 & 6.02 & $\pm 1.14^{b}$ & 4.74 & $\pm 0.86^{c}$ & 4.17 & $\pm 0.83^{c}$ & 5.88 & $\pm 0.68^{d}$ & 0.42 & $\pm 0.06^{c}$ & 42.53 & $\pm 6.59^{\mathrm{de}}$ \\
\hline 30 & 1.31 & $\pm 0.09^{a}$ & 2.37 & $\pm 0.17^{b}$ & 1.87 & $\pm 0.20^{b}$ & 4.55 & $\pm 0.40^{c}$ & 0.38 & $\pm 0.03^{b c}$ & 34.95 & $\pm 0.48^{c d}$ \\
\hline 60 & 0.60 & $\pm 0.08^{a}$ & 1.01 & $\pm 0.03^{a b}$ & 0.67 & $\pm 0.07^{a b}$ & 3.79 & $\pm 0.29^{c}$ & 0.43 & $\pm 0.03^{c}$ & 41.76 & $\pm 6.28^{d}$ \\
\hline 90 & 0.18 & $\pm 0.08^{a}$ & 0.52 & $\pm 0.18^{a}$ & 0.30 & $\pm 0.03^{a}$ & 3.31 & $\pm 0.61^{c}$ & 0.43 & $\pm 0.05^{c}$ & 33.39 & $\pm 3.23^{\mathrm{cd}}$ \\
\hline 120 & 0.07 & $\pm 0.008^{a}$ & 0.17 & $\pm 0.02^{\mathrm{a}}$ & 0.08 & $\pm 0.004^{a}$ & 1.39 & $\pm 0.17^{b}$ & 0.34 & $\pm 0.02^{b c}$ & 23.35 & $\pm 0.49^{c}$ \\
\hline 180 & 0.08 & $\pm 0.004^{a}$ & 0.14 & $\pm 0.02^{a}$ & 0.06 & $\pm 0.01^{a}$ & 0.87 & $\pm 0.05^{a b}$ & 0.28 & $\pm 0.03^{b}$ & 18.94 & $\pm 2.93^{b c}$ \\
\hline 360 & 0.01 & $\pm 0.001^{a}$ & 0.02 & $\pm 0.00^{a}$ & 0.01 & $\pm 0.001^{a}$ & 0.23 & $\pm 0.03^{a}$ & 0.11 & $\pm 0.02^{a}$ & 6.35 & $\pm 0.25^{\mathrm{ab}}$ \\
\hline
\end{tabular}

15

16

17 
18 Figure 1. Mathematical modeling of the degradation of sterol standards during 360-minute thermo-

a) cholesterol

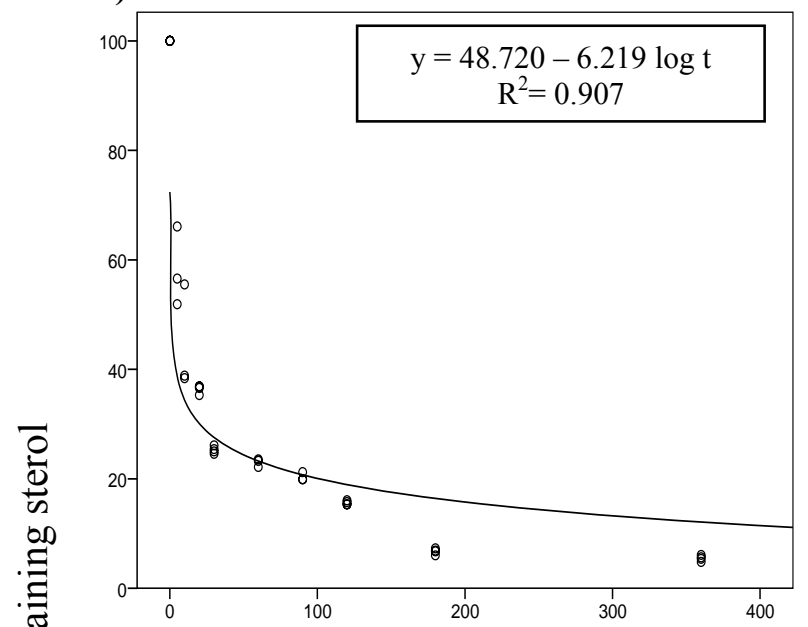

c) stigmasterol

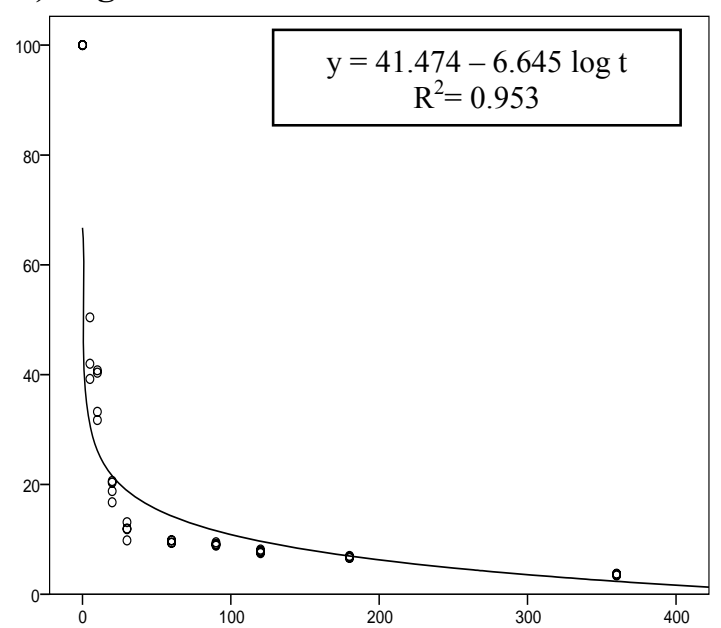

23

24

25

\section{b) campesterol}

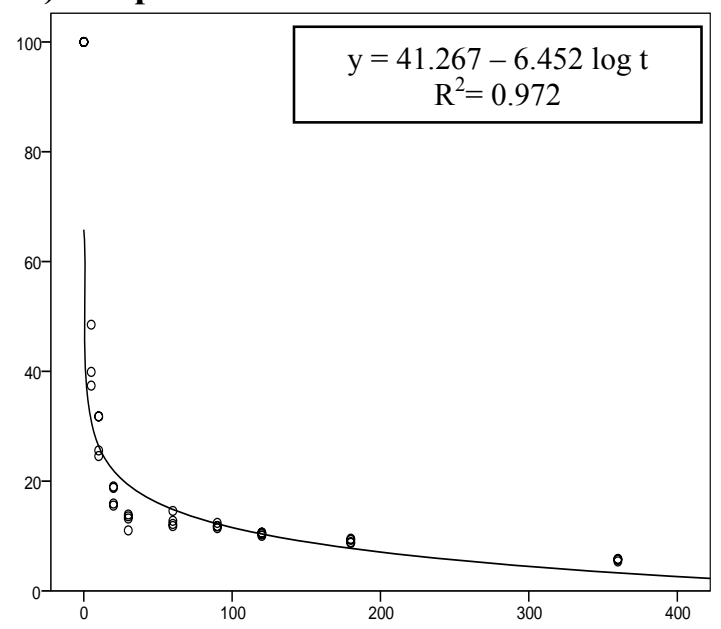

d) $\beta$-sitosterol

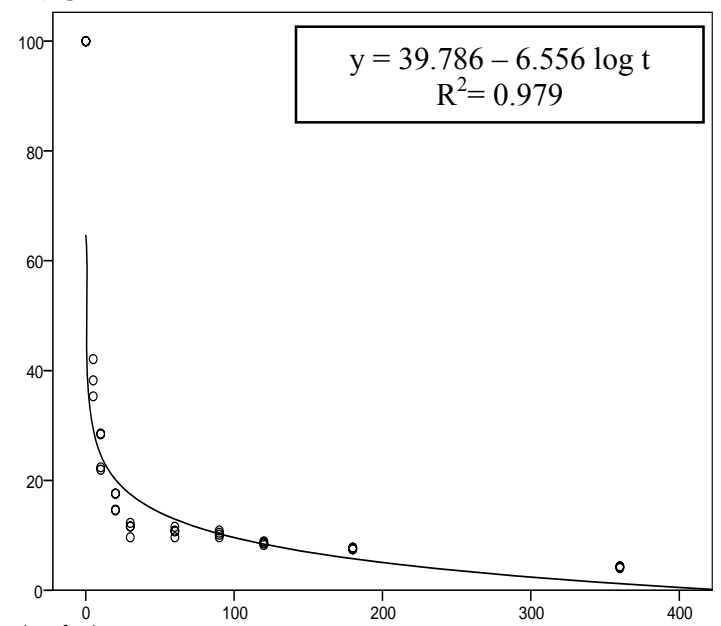

Time (min)

Figure 1. Mathematical modelling of the degradation kinetic of sterol standards during 360-minute thermo-oxidation at $180^{\circ} \mathrm{C}$.Remaining percentages of a) Cholesterol b) Campesterol c) Stigmasterol d) $\beta$-sitosterol 
28 Figure 2. Graphic representations of total SOPs during thermo-oxidation $\left(180^{\circ} \mathrm{C}\right)$ up to $360 \mathrm{~min}$ for

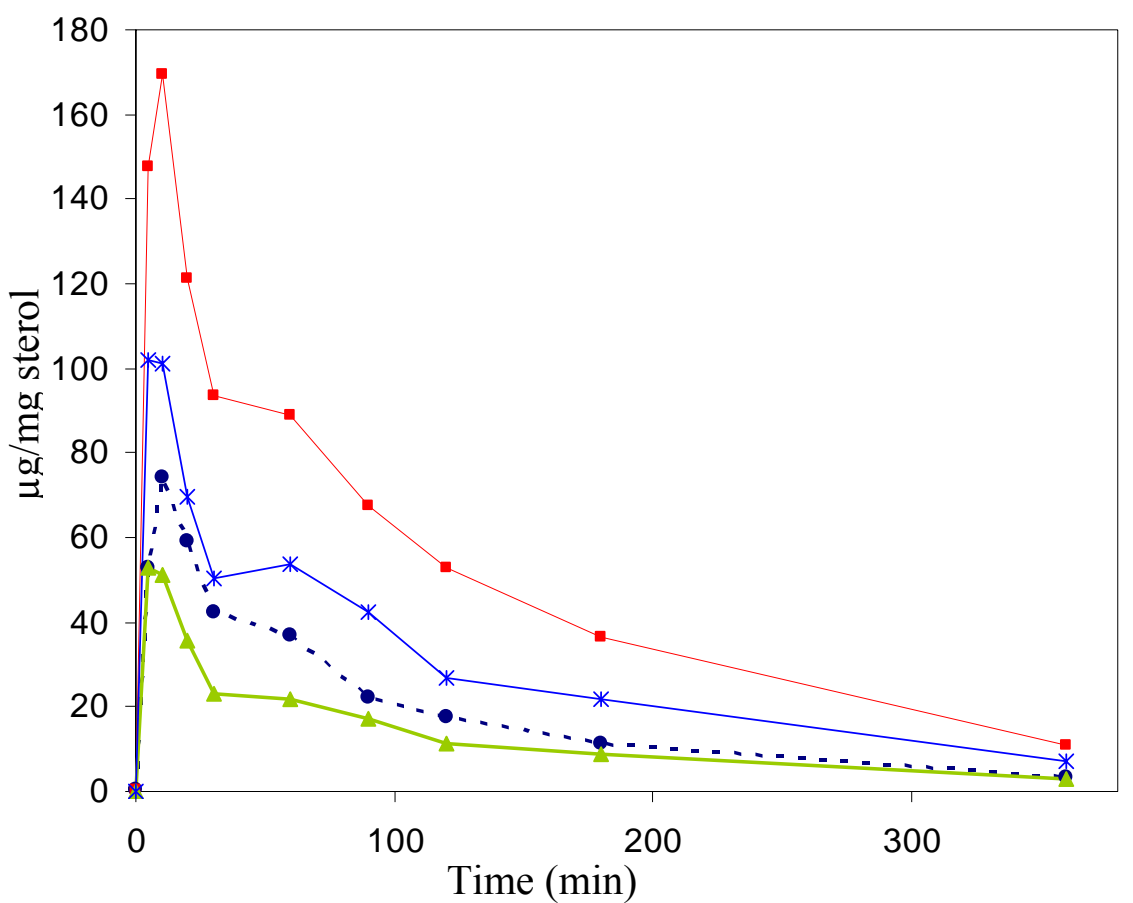

Figure 2. Graphic representations of total SOPs during thermo-oxidation $\left(180^{\circ} \mathrm{C}\right)$ up to $360 \mathrm{~min}$ for different sterol origin - $\rightarrow$ - cholesterol $\longrightarrow$ campesterol $\longrightarrow$ stigmasterol $\longrightarrow$ sitosterol 